Rev. Bras. Saúde Prod. Anim., Salvador, v.17, n.3, p.508-519 jul./set., $2016 \quad$ http://www.rbspa.ufba.br

\title{
Desempenho de bezerros leiteiros recebendo probiótico contendo Bacillus subtilis e Bacillus licheniformis
}

\author{
Performance of calves receiving probiotic containing "Bacillus subtilis" and "Bacillus \\ licheniformis"
}

\author{
TORREZAN, Thais Manzoni ${ }^{1}$; SILVA, Jackeline Thais da ${ }^{1}$; MIQUEO, Evangelina ${ }^{1}$; \\ ROCHA, Nathália Brito ${ }^{1}$; SILVA, Fernanda Lavínia Moura ${ }^{1}$; BALDASSIN, Samyra ${ }^{1}$; \\ BITTAR, Carla Maris Machado ${ }^{1 *}$
}

\author{
${ }^{1}$ Universidade de São Paulo, Escola Superior de Agricultura "Luiz de Queiroz", Departamento de \\ Zootecnia, Piracicaba, São Paulo, Brasil. \\ *Endereço para correspondência: carlabittar@usp.br
}

\section{RESUMO}

Foram utilizados 24 bezerros que receberam 4L/dia de sucedâneo, além de livre acesso a água e concentrado até a $8^{\mathrm{a}}$ semana. Os animais foram distribuídos em delineamento de blocos casualizados, em dois tratamentos: 1) Controle: sem a suplementação de probiótico; 2) Suplementação de $2 \mathrm{~g} / \mathrm{d}$ de Bacillus subtilis e Bacillus licheniformis via sucedâneo lácteo. Semanalmente os animais foram pesados e foram aferidas as medidas corporais; também foram realizadas colheitas de sangue para determinação de glicose, proteína total, ureia e albumina, além de hematócrito. Foram colhidas amostras de fezes semanalmente para contagem de bactérias ácido láticas e enterobactérias e determinação de $\mathrm{pH}$ fecal. O peso corporal, o ganho de peso médio diário e as medidas corporais não foram alteradas pela suplementação; muito embora tenham apresentado efeito significativo de idade dos animais. $\mathrm{O}$ escore fecal, $\mathrm{pH}$ fecal e consumo de concentrado diário também não foram afetados pela suplementação. No entanto, o consumo de concentrado e o $\mathrm{pH}$ fecal sofreram influência da idade em resposta ao crescimento natural dos bezerros. A contagem de bactérias ácido láticas foi maior em número do que a contagem de enterobactérias durante todo o período. Apenas as enterobactérias sofreram efeito da idade, enquanto as bactérias ácido láticas permaneceram variando, porém dentro de um padrão constante. Os parâmetros sanguíneos também não foram afetados pela suplementação com probiótico mas todos, com a exceção da albumina, tiveram influência da idade. A suplementação com o probiótico não apresentou benefícios no desempenho ou no metabolismo de bezerros leiteiros, também não reduziu a ocorrência de casos de diarreia.

Palavras-chave: diarreia, microrganismo intestinais, $\mathrm{pH}$ fecal

\section{SUMMARY}

Twenty-four Holstein calves were utilized and received $4 \mathrm{~L} / \mathrm{d}$ of liquid diet consisting of commercial milk replacer, and had free access to water and starter concentrate. Weaning occurred at the $8^{\text {th }}$ week of age. Animals were distributed in a randomized block design, in the following treatments: 1) Control - without supplementation with probiotic, 2) Supplementation: 2g/d of Bacillus subtilis and Bacillus licheniformis, via milk replacer. Every week calves were weighted and body measurements were taken. Blood samples were drawn weekly for determination of hematocrit, glucose, total protein, urea and albumin. Fecal samples were weekly collected for lactic acid bacteria, enterobacteria couting and fecal $\mathrm{pH}$ determination. Concentrate starter intake and fecal scores were monitored daily. Body weight, average daily gain, and corporal measurements were not affected by the supplementation of probiotic; however, presented a significant age effect. The fecal score, fecal $\mathrm{pH}$ and starter 
intake were not affected by probiotic supplementation. However, starter intake and fecal pH were affected by age due to calves' natural growth. The acid lactic bacteria count was higher than the count of enterobacteria during the whole evaluation period. Only enterobacteria were affected by the age of animals, while acid lactic bacteria remained constant despite little variations. Blood parameters were also not affect by supplementation of probiotic, but all of them, except albumin concentrations, were influenced by age. The supplementation with probiotic containing Bacillus subtilis and Bacillus licheniformis via milk replacer presented no benefits in dairy calves performance or metabolism and did not reduced the occurrence of diarrhea.

Keywords: diarrhea, intestinal microorganisms, performance

\section{INTRODUÇÃO}

Bezerros leiteiros recém nascidos estão sujeitos a ocorrência de diarreia e outros problemas gastrointestinais, os quais resultam em alta taxa de morbidade e possível aumento de mortalidade (NAHMS, 2007).

Em bezerros, a diarreia está relacionada a vários fatores isolados ou em conjunto, referentes ao ambiente, manejo sanitário e nutricional inadequado, além da incapacidade do sistema imunológico em combater agentes patológicos (BENESI, 1999). É muito importante reduzir a prevalência de infecções gastrointestinais em bezerros, pois quando doentes nessa fase, tem seu crescimento futuro e sua produtividade comprometidos (ROSMINI et al., 2004).

Originalmente, os probióticos para animais de produção foram baseados nos potenciais efeitos benéficos (FULLER, 1999), e posteriormente utilizados em alternativa aos antibióticos, visando à manutenção do equilíbrio da microbiota, harmonizando a função digestiva e melhorando a sanidade do animal. Os animais saudáveis, em geral, caracterizam-se por apresentar um bom funcionamento do sistema intestinal, o que garante o equilíbrio da microbiota. Este fator é fundamental para o bom desenvolvimento ou mesmo para incremento da produção (MEYER et al., 2001).

Os probióticos são definidos como aditivos alimentares de microrganismos vivos os quais os benefícios afetam o animal hospedeiro melhorando $\mathrm{o}$ equilíbrio da microbiota intestinal (FULLER et al.,1989). Segundo Vanbelle et al. (1990), após uma dosagem oral efetiva, são capazes de estabelecer-se no trato gastrintestinal e manter ou aumentar a microbiota natural, ajudando a prevenir a colonização por microrganismos patogênicos, assegurando melhor utilização dos nutrientes (HOLZAPFEL et al., 2001; SCHAREK et al., 2005; GUO et al., 2006).

Há inúmeros trabalhos verificando a utilização de probióticos em bezerros, pois as primeiras semanas de vida são muito importantes para seu desenvolvimento e produção futuros. Alguns destes trabalhos mostram melhora no desempenho dos animais (KAWAKAMI et al., 2010; KOWALSKI et al., 2009; JATKAUSKAS et al., 2010), diminuição na incidência de diarreia (JATKAUSKAS et al., 2010; KIM et al., 2011), enquanto outros autores não tiveram efeitos significativos (BAYATKOUHSAR et al., 2013; FRIZZO et al., 2010). O que se destaca em alguns destes trabalhos é que os efeitos esperados dos probióticos apresentam-se mais significativos quando os animais estão sob estresse (TIMMERMAN et al., 2005; CRUYAGEN et al., 1995, RIDELL et al., 2010), o que ocorre geralmente até as duas primeiras semanas de vida.

Objetivou-se com esse estudo avaliar se a suplementação de probiótico contendo 
Rev. Bras. Saúde Prod. Anim., Salvador, v.17, n.3, p.508-519 jul./set., $2016 \quad \underline{\text { http://www.rbspa.ufba.br }}$ ISSN 15199940

Bacillus subtilis e Bacillus licheniformis, fornecido via sucedâneo, pode beneficiar bezerros leiteiros no que se refere a saúde, o desempenho geral e metabolismo de bezerros leiteiros.

\section{MATERIAL E MÉTODOS}

O experimento foi conduzido no Bezerreiro Experimental "Evilásio de Camargo" do Departamento de Zootecnia da Escola Superior de Agricultura "Luiz de Queiroz", ESALQ/USP, Piracicaba, São Paulo. O estudo foi conduzido sob aprovação do protocolo do Comitê de Ética em Pesquisa Animal da Escola Superior de Agricultura "Luiz de Queiroz".

Foram utilizados 24 bezerros machos da raça holandesa, provenientes do rebanho da Fazenda Agrindus Ltda, Descalvado, SP, Brasil. Após o nascimento, foram separados de suas mães e então fornecidos $4 \mathrm{~L} / \mathrm{d}$ de colostro, em duas refeições diárias, até o segundo dia de vida. Após, foram transportados ao bezerreiro experimental onde foram alojados individualmente em casinhas estilo tropical, sendo contidos por corrente de $1,80 \mathrm{~m}$ de comprimento, impedindo deste modo o contato físico entre os bezerros, e permitindo que o animal esteja sempre em local seco e limpo de fezes, sendo dispostos em local plano com gramado, orientados de tal modo para que em todo momento do dia o animal possuísse sombra ao seu alcance.

Os animais foram distribuídos em blocos, considerando-se o peso ao nascer, e então alocados em um dos tratamentos: 1) suplementação com probiótico Bioplus, composto por Bacillus licheniformis, Bacillus subtilis, aluminosilicato de sódio e maltodextrina(Ouro Fino SA, Ribeirão Preto, SP, Brasil), na dose de $2 \mathrm{~g} / \mathrm{d}$, a qual foi adicionada ao sucedâneo lácteo no momento do seu fornecimento; e 2) controle, fornecimento de sucedâneo sem adição de probiótico. $\mathrm{O}$ sucedâneo foi fornecido no volume de 4L/d (Feedtech, De Laval Ltda., Campinas, São Paulo, Brasil), dividido em duas refeições diárias ( $7 \mathrm{~h}$ e $17 \mathrm{~h}$ ), e os animais tiveram livre acesso ao concentrado inicial comercial (Ração Bezerra Ag Milk Agroceres Multimix Nutrição Animal Ltda., Rio Claro, São Paulo, Brasil) e água desde o momento em que foram alojados no bezerreiro. $\mathrm{O}$ concentrado foi fornecido toda manhã, ad libitum pesando-se a sobra do dia anterior, de forma a se obter o consumo diário de concentrado. A mistura do sucedâneo com probiótico foi feita na ESALQ/USP, de acordo com as instruções do fabricante do probiótico.

Tabela 1. Composição químico-bromatológica do sucedâneo lácteo e concentrado inicial

\begin{tabular}{lcc}
\hline Item & \multicolumn{2}{c}{ Alimentos } \\
\cline { 2 - 3 } & Sucedâneo & Concentrado $^{2}$ \\
\hline Matéria Seca, \% & 96,05 & 90,68 \\
Matéria Mineral, \% MS & 6,16 & 7,16 \\
Proteína Bruta, \% MS & 20,05 & 24,57 \\
Extrato Etéreo, \% MS & 15,46 & 4,29 \\
FDN, \% MS & 0,65 & 18,12 \\
Nutrientes digestíveis totais (NDT) & - & 83,05 \\
Energia Bruta, Mcal/kg & $4.557,92$ & - \\
\hline 'Feedtech, De Laval Ltda., Campinas, São Paulo, Brasil (12,5\% de sólidos); ${ }^{2}$ Ração Bezerra Ag Milk &
\end{tabular}


Os animais foram pesados ao nascer e semanalmente, em balança mecânica, sempre antes do fornecimento da dieta líquida do período da manhã, até a $8^{\mathrm{a}}$ semana de vida, quando se encerrou o período experimental. Foram também tomadas semanalmente medidas de altura na cernelha, largura na garupa e perímetro torácico.

O monitoramento do escore fecal foi realizado através de observações visuais diárias, utilizando-se adaptações do método descrito por Larson et al. (1977), quanto a fluidez das fezes. As fezes foram classificadas em normal (1); mole (2); corrente (3); aquosa (4) ou consistência líquida (5).

$\mathrm{O} \mathrm{pH}$ fecal foi medido logo após a coleta das amostras, sendo utilizados aproximadamente $10 \mathrm{~g}$ de fezes frescas homogeneizadas com $10 \mathrm{~mL}$ de água destilada, e leitura direta em $\mathrm{pH}$ metro (Tec-5, Tecnal ltda., Piracicaba, SP, Brasil). Uma alíquota foi utilizada para contagem dos microrganismos intestinais conforme Kawakami et al. (2010). Cerca de $1 \mathrm{~g}$ de amostra foi homogeneizado em $9 \mathrm{~mL}$ de água destilada esterilizada, para a realização de diluições seriadas de $10^{-1}$ a $10^{-10}$. De cada diluição foram retiradas alíquotas de $50 \mu 1$ para contagem de enterobactérias e bactérias ácido-láticas (BAL). Placas Petrifilm ${ }^{\mathrm{TM}}$ (3M do Brasil®, Sumaré, SP, Brasil) foram utilizadas para contagem de enterobactérias. As mesmas foram incubadas a $32,5 \pm 1^{\circ} \mathrm{C}$ em incubadora BOD Modelo TE-402 (Tecnal, Piracicaba, SP, Brasil) por $24 \pm 2$ horas. Após o período de incubação, a contagem prosseguiu, considerando as colônias vermelhas com zonas amarelas e/ou colônias vermelhas com bolhas de gás, com ou sem bordas amarelas como positivas para enterobactérias. A contagem de BAL também foi realizada com auxílio de placas do tipo
Petrifilm ${ }^{\circledR} \quad$ AC $\quad\left(3 \mathrm{M}\right.$ do Brasil ${ }^{\circledR}$, Sumaré, SP, Brasil), as placas foram incubadas em jarras de anaerobiose com gerador de atmosfera de anaerobiose (ANAEROBAC, Probac do Brasil Produtos Bacteriológicos Ltda., São Paulo, SP, Brasil), em estufa BOD Modelo TE-402 (Tecnal, Piracicaba, SP, Brasil) por $48 \pm 3$ horas.

As placas utilizadas para contagem continham de 30 a 300 colônias. Os valores das contagens foram correlacionados com as respectivas diluições e os resultados apresentados em unidades formadoras de colônia (UFC). Para ajustar as contagens, as amostras de fezes foram submetidas a secagem em estufa a $105^{\circ} \mathrm{C}$, para determinação de matéria seca (MS), de forma que o peso inicial da amostra pudesse ser corrigido. Assim, os valores foram expressos em UFC/g de MS de fezes.

Amostras de sangue foram colhidas semanalmente, a partir da segunda semana de vida, sempre duas horas após o fornecimento da dieta da manhã, através de punção da jugular; utilizando-se tubos vacuolizados contendo fluoreto de sódio como antiglicolítico e EDTA de potássio como anticoagulante. Uma alíquota do sangue foi destinada para a determinação de hematócrito, sendo o restante das amostras centrifugadas a 2000 x $g$, durante 20 minutos, a temperatura de $4^{\circ} \mathrm{C}$ para a obtenção do plasma. O plasma foi armazenado em microtubos plásticos os quais mantidos em freezer para posterior determinação de glicose plasmática, proteína total, albumina e N-uréico.

As amostras de sangue destinadas para hematócrito, colhidas semanalmente, foram acondicionadas em tubos capilares para micro hematócrito (Classcyto $\left.{ }^{\circledR}\right), \quad$ sem heparina, preenchendo-se cerca de $3 / 4$ dos tubos. 
Rev. Bras. Saúde Prod. Anim., Salvador, v.17, n.3, p.508-519 jul./set., $2016 \quad \underline{\text { http://www.rbspa.ufba.br }}$

Os tubos capilares foram centrifugados em centrífuga de microhematócrito Modelo SPIN 1000 (MICROSPIN), a $12.000 \times \mathrm{x}$, por 10 minutos. Após centrifugação, a leitura dos valores de hematócrito foi realizada em régua própria para este fim, e os resultados expressos em porcentagem.

As análises de glicose, proteínas totais, albumina e ureia foram realizadas utilizando kit enzimático (LABTEST Diagnóstica S.A., Lagoa Santa, MG, Brasil) seguindo as orientações do fabricante, com a leitura realizada em Sistema Automático para Bioquímica Modelo SBA 200 (CELM, Barueri, SP, Brasil).

Os dados de desempenho como peso corporal, consumo de concentrado e ganho de peso diário foram analisados como medidas repetidas no tempo através do procedimento MIXED do pacote estatístico SAS (9.1), conforme modelo (1). Para efeito de comparação de médias foi utilizado o teste $t$ de Student, sendo as médias estimadas através do método dos quadrados mínimos (LSMEANS), com nível de significância de 5\%.

$Y_{i j k}=\mu+T_{i}+l_{j}+T I_{i j}+B_{k}+e_{i j k}$

Em que: $Y_{\mathrm{ijk}=}$ variável resposta; $\mu=$ média geral; $\mathrm{T}_{\mathrm{i}}=$ Efeito de tratamento; $\mathrm{I}_{\mathrm{j}}=$ efeito de idade; $\mathrm{TI}_{\mathrm{ij}}=$ interação Tratamento $\mathrm{X}$ Idade; $\mathrm{B}_{\mathrm{k}}=$ Efeito de bloco; $\mathrm{e}_{\mathrm{ijk}}=$ erro experimental.

\section{RESULTADOS E DISCUSSÃO}

Os resultados mostram que o consumo de concentrado não foi afetado pela suplementação de probiótico $(\mathrm{P}>0,05)$. Do mesmo modo, não houve efeito significativo para a interação Tratamento $\mathrm{x}$ Idade, houve, como esperado, efeito significativo para a idade $\quad(\mathrm{P}<0,0001) \quad$ com aumentos constantes até a oitava semana de vida dos animais, devido à crescente necessidade de consumir alimento sólido com o avançar da idade (QUIGLEY, 2001).

Tabela 2. Consumo de concentrado (g/dia), peso corporal $(\mathrm{kg})$ e ganho de peso diário $(\mathrm{g} / \mathrm{d})$ de bezerros suplementados ou não com probiótico contendo Bacillus subtilis e Bacillus licheniformis (BioPlus)via sucedâneo

\begin{tabular}{|c|c|c|c|c|c|c|}
\hline \multirow{2}{*}{ Item } & \multicolumn{2}{|c|}{ Tratamentos } & \multirow{2}{*}{$\mathrm{EPM}^{1}$} & \multicolumn{3}{|c|}{$\mathrm{P}<{ }^{2}$} \\
\hline & Controle & BioPlus & & $\mathrm{T}$ & I & $\mathrm{T} \times \mathrm{I}$ \\
\hline Consumo de concentrado, $\mathrm{g} / \mathrm{d}$ & 372,8 & 362,0 & 28,59 & 0,89 & $<0,0001$ & 0,72 \\
\hline \multicolumn{7}{|l|}{ Peso corporal, $\mathrm{Kg}$} \\
\hline Inicial & 36,5 & 35,4 & 0,82 & 0,48 & - & - \\
\hline Final & 57,4 & 57,2 & 1,99 & 0,92 & - & - \\
\hline Média do período total & 43,3 & 43,1 & 0,67 & 0,93 & $<0,0001$ & 0,9 \\
\hline \multicolumn{7}{|l|}{ Ganho de peso, g/d } \\
\hline Média do período & 367,4 & 436,9 & 30,22 & 0,34 & $<0,0001$ & 0,72 \\
\hline
\end{tabular}


A ausência de efeito significativo no consumo de bezerros suplementados com probiótico, contendo cepas de bactérias ácido láticas, também foi observado por Cruywagen et al. (1996) e Kim et al. (2011), que apresentaram valores de consumo semelhantes ao deste trabalho. Frizzo et al. (2011) que também estudaram o efeito de cepas de bactérias ácido láticas em bezerros, observaram consumo de concentrado até 3 vezes maior que os valores observados no presente estudo, provavelmente devido ao fornecimento dessas cepas sob condições de estresse nutricional.

Stamey et al. (2012) afirmam que monitorar o consumo de concentrado antes do desaleitamento é um manejo de extrema importância e recomendam o consumo de pelo menos $1 \mathrm{~kg} / \mathrm{d}$ antes do desaleitamento para assegurar $\mathrm{o}$ crescimento contínuo do animal sem prejuízos com a retirada da dieta líquida.

O peso corporal e o ganho de peso diário (Tabela 2) também não sofreram influência da suplementação de probiótico $(\mathrm{P}>0,05)$. No entanto houve efeito da idade, já que os animais estavam em crescimento e houve aumento no consumo de concentrado com o avançar da idade. A queda de peso corporal ocorrida na segunda semana de vida dos animais reflete o aumento dos casos de diarreia ocorridos principalmente durante até os primeiros 15 dias de vida, fato comum na maior parte dos sistemas de criação. Jatkauskas \& Vrotniakiene (2010) testaram uma cepa de bactéria ácido lática, Enterococcus faecium, e tiveram grande diferença entre os pesos corporais dos bezerros quando comparados os grupos tratamento $\mathrm{e}$ controle, com valores de até $7,6 \mathrm{~kg}$ maiores no grupo que recebeu probiótico, em 56 dias de experimento. Sun et al. (2010), utilizou cepas de Bacillus subtilis natto durante a fase de aleitamento em bezerros suplementados no sucedâneo. Os animais suplementados apresentaram a eficiência alimentar $18 \%$ maior do que os animais do grupo controle.

$\mathrm{O}$ ganho de peso médio diário não foi afetado pela suplementação com probiótico (Tabela 2). Houve uma redução no ganho de peso dos animais da primeira para a segunda semana de experimento, o qual pode ser devido ao estresse da viagem, estresse de mudança de ambiente e volume de sucedâneo limitado, o que pressiona o animal a iniciar a ingestão de concentrado. Essa inclusão de uma nova alimentação, pode causar perda de peso, devido ao intervalo entre o animal iniciar o consumo até alcançar a ingestão suficiente. Observouse também que durante a quarta e a quinta semana, houve uma diminuição no ganho de peso, provavelmente pelo aumento da diarreia nas duas semanas anteriores.

As medidas de crescimento não foram afetadas pela suplementação com probiótico e também não houve efeito para a interação Tratamento $\mathrm{x}$ Idade, houve sim, efeito significativo para Idade ( $\mathrm{P}<0,0001$; Tabela 3). Apesar da ausência de efeito significativo, os animais suplementados com probiótico apresentaram médias numéricas de ganhos semanais maiores do que o grupo controle, principalmente nos parâmetros de perímetro torácico e altura de cernelha. A maioria dos dados de ganho/semana de altura na cernelha do presente estudo estão abaixo da média recomendada por Hoffman (1997), que indica valores médios em torno de $1,3 \mathrm{~cm} / \mathrm{semana}$ para animais da raça holandesa, porém a média de altura de cernelha do grupo suplementado com probiótico, está dentro do valor recomendado de $80,6 \mathrm{~cm}$ em 60 dias de vida dos animais. Os resultados observados demonstram que tanto os animais recebendo probióticos como os animais do tratamento controle obtiveram crescimento positivo contínuo de acordo com a evolução da idade. 
Rev. Bras. Saúde Prod. Anim., Salvador, v.17, n.3, p.508-519 jul./set., $2016 \quad \underline{\text { http://www.rbspa.ufba.br }}$ ISSN 15199940

Tabela 3. Altura de cernelha, perímetro torácico e largura de garupa de bezerros recebendo ou não suplementação de probiótico contendo Bacillus subtilis e Bacillus licheniformis via sucedâneo

\begin{tabular}{|c|c|c|c|c|c|c|}
\hline \multirow{2}{*}{ Parâmetro } & \multicolumn{2}{|c|}{ Tratamento } & \multirow{2}{*}{$\mathrm{EPM}^{1}$} & \multicolumn{3}{|c|}{$\mathrm{P}<2$} \\
\hline & Controle & BioPlus & & $\mathrm{T}$ & I & Tx I \\
\hline \multicolumn{7}{|l|}{ Altura na cernelha, $\mathrm{cm}$} \\
\hline Média do período total & 74,7 & 80,9 & 0,23 & 0,70 & $<, 0001$ & 0,86 \\
\hline Ganho, cm/semana & 0,84 & 1,01 & 0,66 & 0,35 & 0,001 & 0,88 \\
\hline \multicolumn{7}{|l|}{ Perímetro torácico, cm } \\
\hline Média do período total & 80,1 & 80,4 & 0,40 & 0,71 & $<, 0001$ & 0,39 \\
\hline Ganho, cm/semana & 1,78 & 2,03 & 0,63 & 0,49 & 0,01 & 0,64 \\
\hline \multicolumn{7}{|l|}{ Largura da garupa, $\mathrm{cm}$} \\
\hline Média do período total & 20,3 & 22,1 & 0,09 & 0,68 & $<, 0001$ & 0,86 \\
\hline Ganho, $\mathrm{cm} /$ semana & 0,40 & 0,42 & 0,12 & 0,99 & 0,62 & 0,79 \\
\hline
\end{tabular}

${ }^{1} \mathrm{EPM}=$ erro padrão da média; ${ }^{2} \mathrm{~T}$ = efeito de tratamento; $\mathrm{I}$ = efeito de idade; TxI: efeito de interação Tratamento x Idade.

No estudo não houveram diferenças significativas entre o escore fecal dos bezerros do grupo suplementado por probiótico e dos animais do grupo controle ao longo das 8 semanas de experimento. Segundo Larson et al. (1977), escores maiores ou iguais a 3 são considerados diarreia, o que no presente estudo, se verificou principalmente na segunda semana de vida dos animais. Henrichs et al. (2009) obteve escores fecais similares em seus animais, independente do tratamento, exibindo um padrão típico assim como no presente estudo, com um pico na segunda semana seguido por declínio e estabilização em escore $1 \mathrm{em}$ torno da sexta semana de vida dos animais. Kowalski et al. (2009) também realizou um experimento onde testou as mesmas cepas bacterianas utilizadas no presente estudo, utilizando animais a partir de 15 dias de idade, onde também não obteve diferenças com relação ao escore fecal dos bezerros que utilizaram o probiótico e os animais do grupo controle.

$\mathrm{O}$ pH fecal não sofreu efeito da suplementação do probiótico no período avaliado. Durante a segunda semana, o valor do $\mathrm{pH}$ fecal do grupo controle foi menor em relação ao grupo suplementado $(6,13$ vs 6,68). Esses resultados podem estar relacionados ao período de maior incidência de diarreia e uma provável mudança na população de microrganismos intestinais, sugerindo um aumento da população de enterobactérias, apesar da ingestão do probiótico. No restante do período, o grupo suplementado apresentou valores de $\mathrm{pH}$ fecal menores que o grupo controle.

A contagem de enterobactérias apresentou-se menor durante todo $\mathrm{o}$ período avaliado em relação ao número de bactérias ácido-láticas (BAL) (Tabela 4). Além disso, a contagem de enterobactérias apresentou efeito para idade $(\mathrm{P}<0,05)$, ocorrendo uma grande diminuição de colônias conforme $\mathrm{o}$ passar das semanas. O mesmo efeito porém, não ocorreu com as BAL, que apresentou variação ao longo das semanas, contudo, mantendo um mesmo padrão de colonização. 
Rev. Bras. Saúde Prod. Anim., Salvador, v.17, n.3, p.508-519 jul./set., $2016 \quad \underline{\text { http://www.rbspa.ufba.br }}$ ISSN 15199940

Tabela 4. Média da contagem de enterobactérias e bactérias ácido láticas $(\log 10$ UFC/gMS) de bezerros recebendo ou não suplementação de probiótico (BioPlus) contendo Bacillus subtilis e Bacillus licheniformis via sucedâneo

\begin{tabular}{lcccccc}
\hline \multirow{2}{*}{$\log 10$ UFC/g MS } & \multicolumn{2}{c}{ Tratamentos } & \multirow{2}{*}{ EPM $^{1}$} & \multicolumn{3}{c}{$\mathrm{P}<^{2}$} \\
\cline { 2 - 3 } \cline { 6 - 8 } & Controle & BioPlus & & $\mathrm{T}$ & $\mathrm{I}$ & TxI \\
\hline Enterobactérias & 6,79 & 7,38 & 0,82 & 0,62 & 0,04 & 0,94 \\
Bactérias ácido-láticas & 10,86 & 10,54 & 0,39 & 0,56 & 0,64 & 0,42 \\
pH fecal médio & 6,78 & 6,74 & 0,06 & 0,64 & 0,04 & 0,13 \\
\hline
\end{tabular}

${ }^{1} \mathrm{EPM}=$ erro padrão da média; ${ }^{2} \mathrm{~T}$ = efeito de tratamento; $\mathrm{I}=$ efeito de idade; TxI: efeito de interação Tratamento x Idade.

Ellinger et al. (1980) forneceram Lactobacillus acidophilus durante 3 semanas para bezerros, verificando menor contagem de colônias de enterobactérias nos animais suplementados, porém o número de BAL foi maior nos animais do grupo controle. Isso pode ser explicado por dados da literatura (HENRICHS et al., 2009; RIDELL et al., 2010; FRIZZO et al., 2010) que defendem que a suplementação de probióticos só é efetiva quando os animais estão sob condições de estresse. Jenny et al. (1991) ao fornecer uma mistura probiótica contendo Lactobacillus e Bacillus a bezerros durante 30 dias, também não obteve aumento da contagem fecal de BAL. Segundo esses mesmo autores, a contagem de BAL mantendo-se sempre maior que a de enterobactérias, revela uma flora intestinal já balanceada, que provavelmente não será afetada pelo uso de probióticos (Tabela 5).

Tabela 5. Parâmetros sanguíneos de bezerros recebendo ou não suplementação de probiótico contendo Bacillus subtilis e Bacillus licheniformis via sucedáneo

\begin{tabular}{|c|c|c|c|c|c|c|}
\hline \multirow{2}{*}{ Variáveis } & \multicolumn{2}{|c|}{ Tratamentos } & \multirow{2}{*}{$\mathrm{EPM}^{1}$} & \multicolumn{3}{|c|}{$\mathrm{P}<{ }^{2}$} \\
\hline & Controle & Probiótico & & $\mathrm{T}$ & I & $\mathrm{T} \times \mathrm{I}$ \\
\hline Hematócrito, \% & 21,2 & 20,5 & 0,61 & 0,61 & $<, 0001$ & 0,28 \\
\hline Ureia, mg/dL & 19,5 & 18,8 & 1,44 & 0,69 & 0,02 & 0,06 \\
\hline Glicose, $\mathrm{mg} / \mathrm{dL}$ & 102,7 & 104,4 & 1,47 & 0,811 & 0,023 & 0,789 \\
\hline Proteína total, $\mathrm{g} / \mathrm{dL}$ & 7,0 & 7,2 & 0,17 & 0,532 & $<, 0001$ & 0,192 \\
\hline Albumina, g/ dL & 2,5 & 2,5 & 0,64 & 0,849 & 0,13 & 0,266 \\
\hline
\end{tabular}

${ }^{\mathrm{I}} \mathrm{EPM}=$ erro padrão da média; ${ }^{2} \mathrm{~T}$ = efeito de tratamento; $\mathrm{I}=$ efeito de idade; TxI: efeito de interação Tratamento x Idade.

Os valores médios de hematócrito não foram afetados pela suplementação de probiótico $(\mathrm{P}>0,05)$. Nas primeiras semanas, os valores de hematócrito apresentaram-se mais altos, e com o avanço da idade, os valores de hematócrito diminuíram ( $\mathrm{P}>0,0001)$, até a sexta semana, quando então houve novo aumento até a oitava semana. Essa queda até a sexta semana de vida está de acordo com outros dados na literatura (TAO et al., 2012; HULBERT et al., 2011), mas o aumento que ocorre nas duas últimas semanas pode ser devido a desidratação.

A concentração de ureia não foi afetada $(\mathrm{P}>0,05)$ pela suplementação de probiótico, houve no entanto, efeito da idade $(\mathrm{P}<0,05)$. Assim que o animal nasce, os rins assumem a função de excreção que antes era realizada pela 
placenta, além de também ser encarregado do balanço hidroeletrolítico, por isso a influência da idade dos bezerros sobre os níveis de ureia sérica, revelando o crescente avanço da eficiência da função renal com o avançar da idade. Gregory et al. (2004) obteve valores de $18,49 \pm 4,5 \mathrm{mg} / \mathrm{dL}$ em bezerras de até 3 meses de idade.

A suplementação com probiótico não afetou $(\mathrm{P}>0,05)$ a concentração média de glicose durante as 8 semanas de experimento (Tabela 5). A interação Tratamento $\mathrm{x}$ Idade também não apresentou-se significativa, porém houve efeito da idade $(\mathrm{P}<0,05)$, assim como observado por Quigley et al. (1997) que encontraram valores de $114 \mathrm{mg} / \mathrm{dL}$ em bezerros com 1 semana de vida e valores em torno de $76 \mathrm{mg} / \mathrm{dL}$ em bezerros depois de 2 a 3 semanas já desaleitados. Esses dados estão em acordo com Mohri et al. (2006) que em bezerros com 24-48h de vida encontraram valores de glicose de $115 \mathrm{mg} / \mathrm{dL}$ e em bezerros com 56 dias de vida encontraram valores em torno de $72 \mathrm{mg} / \mathrm{dL}$. No presente estudo não foi possível observar decréscimos mais acentuados de valores, pois não houve medições após o desaleitamento, onde seria o período de maior evidência.

A proteína total não apresentou efeito da suplementação de probiótico $(\mathrm{P}>0,05)$. Apresentou efeito da idade, ocorrendo queda após a primeira semana, devido a diminuição de proteínas circulantes ingeridas do colostro, e após a $6^{\mathrm{a}}$ semana um aumento significante, provavelmente devido ao início da produção pelo próprio animal (KANECO et al., 2000). Outro motivo possível é devido ao aumento da ingestão de proteína pela dieta, já que a diminuição das proteínas totais no plasma está relacionada a deficiência na alimentação, quando descartadas causas patológicas. Esse parâmetro pode ser usado para avaliar a eficiência da alimentação dos animais (GONZÁLEZ et al, 2000).
A concentração sérica de albumina, assim como os outros parâmetros, não apresentou diferenças estatísticas entre os tratamentos, e nem efeito com relação a idade $(\mathrm{P}>0,05)$. Jezek et al. (2005) obteve resultados com tendências semelhantes ao presente estudo, com média em 8 semanas de 2,72g/dL. Egli \& Blum (1997) observaram queda nos valores de albumina do dia 0 para o dia 1 de vida dos bezerros, seguida de aumento e de concentrações que permaneceram estáveis até os 84 dias.

Os resultados reportados na literatura sobre o uso de probióticos para fins terapêuticos ou como promotor de crescimento em bezerros são heterogêneos, não consistentese nem sempre positivos. A resposta do animal ao uso deprobióticos é influenciada pelo tipo de produto, pela doseutilizada, idade e raça do animal, tipo de exploração e demanejo, uso concomitante de antibióticos e o ambiente decriação.

Por esse estudo, conclui-se que a suplementação com o probiótico contendo Bacillus subtilis e Bacillus licheniformis (BioPlus) via sucedâneo não apresenta benefícios no desempenho ou no metabolismo de bezerros leiteiros, bem como não reduz a ocorrência de casos de diarreia.

\section{REFERÊNCIAS}

BAYATKOUHSAR, J.; TAHMASEBI, A.M.; NASERIAN, A.A.;

MOKARRAM, R.R.; VALIZADEH, R. Effects of supplementation of latic acid bacteria on growth performance, blood metabolites and fecal coliform and lactobacilli of young dairy calves.

Animal Feed Science and Technology, v.186, p.1-11, 2013. 
Rev. Bras. Saúde Prod. Anim., Salvador, v.17, n.3, p.508-519 jul./set., $2016 \quad \underline{\text { http://www.rbspa.ufba.br }}$ ISSN 15199940

BENESI, F.J. Síndrome diarreia dos bezerros. Revista CRMV-ES, v.2, n.3, p.10-13, 1999.

CRUYWAGEN, C.W.; JORDAN, I.; VENTER, L. Effect of Lactobacillus acidophilus supplementation of milk replacer on pre weaning performance of dairy calves. Journal of Dairy Science, v.79, p.483-486, 1996.

EGLI, C.P.; BLUM, J.W. Clinical, haematological, metabolic and endocrine traits during the first three months of fife of suckling simmentaler calves held in a cow-calf operation. Journal of Veterinary Medicine, v.45, p.99-118, 1997.

ELLINGER, D.K.; MULLER, L.D.; GLANTZ, P.J. Influence of feeding fermented colostrum and Lactobacillus acidophilus on fecal flora of dairy calves. Journal of Dairy Science, v.63, p.478482,1980 .

FRIZZO, L.S.; SOTTO, L.P.; ZBRUN, M.V.; BERTOZZI, E.; SEQUEIRA, G.; ARMESTO, R.R.; ROSMINI, M. R. Lactic acid bacteria to improve growth performance in young calves fed milk replacer and spray-dried whey powder. Animal Feed Science and Technology, v.157, p.159-167, 2010.

FRIZZO, L.S.; ZBRUN, M.V.; SOTO, L.P.; SIGNORINI, M.L. Effect of probiotics on the growth performance in young calves: a meta-analysis of randomized controlled trials. Animal Feed Science and Technology, v.169, p.147-156, 2011.

FULLER, R. A review: probiotics in man and animals. Journal of Applied Bacteriology, v.66, p.365-378, 1989.

FULLER, R.; TANNOCK, G.W. Probiotics for farm animals. Wymondham, UK: Horizon Scientific Press, 1999
GONZÁLEZ, F.H.D.; BARCELLOS, J.; PATIÑO, H.O.;RIBEIRO, L.A. (Ed.). Perfil metabólico em ruminantes: seu uso em nutrição e doenças nutricionais. Porto Alegre, 2000. 106 p.

GREGORY, L.; BIRGEL JUNIOR, E.H.; D'ANGELINO, F.J.; BENESI, F.J.;

BIRGEL, E.H. Valores de referência dos teores séricos da ureia e creatinina em bovinos da raça Jersey criados no Estado de São Paulo. Influência dos fatores etários, sexuais e da infecção pelo vírus da leucose dos bovinos. Arquivos do Instituto Biológico, v.71, n.3, p.339-345, 2004.

GUO, X.; LI, D.F.; LU, W.Q.; PIAO, X.S.; CHEN, X.L. Screening of Bacillus strains as potential probiotics and subsequent confirmation of the in vivo effectiveness of Bacillus subtilis MA139 in pigs. Antonie Van Leeuwenhoek, v.90, p.139-146, 2006.

HEINRICHS, A.J.; JONES, C.M.; ELIZONDO-SALAZAR, J.A.;

TERRILL, S.J. Effects of a prebiotic supplement on health of neonatal dairy calves. Livestock Science, v.125, p.149154, 2009.

HOFFMAN, P.C. A new look at our old heifer-rasing rules. Hoard's Dairyman, v.142, n.9, p.814-827, 1997.

HOLZAPFEL, W.H.; HABERER, P.; GEISEN, R.; BJORKROTH, J.; SCHILLINGER, U. Taxonomy and important features of probiotic microorganisms in food and nutrition.

American Journal of Clinical

Nutrition, v.73, p.365-373, 2001.

HULBERT, L.E, C.J. COBB, J.A. CARROLL, M.A. BALLOU. The effects of early weaning on innate immune responses of Holstein calves. Journal of Dairy Science, v.94, p.2545-2556, 2011. 
Rev. Bras. Saúde Prod. Anim., Salvador, v.17, n.3, p.508-519 jul./set., $2016 \quad \underline{\text { http://www.rbspa.ufba.br }}$ ISSN 15199940

JATKAUSKAS, J.; VROTNIAKIENE, $\mathrm{V}$. Effects of probiotic dietary supplementation on diarrhea patterns, faecal microbiota and performance of early weaned calves. Veterinarni Medicina, v.55, p.494-503, 2010.

JENNY, B.; VANDJK, F.; COLLINS, H.J. Performance and fecal flora of calves fed a Bacillus subtilis concentrate. Journal of Dairy Science, v.74, p.1968-1973, 1991.

JESEK, J.; KLOPICIC, M.; KLINKON, $\mathrm{M}$. Influence of age on biochemical parameters in calves. Bulletin of the Veterinary Institute in Pulaway, v.50, p.211-214, 2005.

KANEKO, J.J.; HARVEY, J.W.; BRUSS, M.L. Clinical biochemistry of domestic animals. $6^{\text {th }}$ ed. England : Elsevier Academic Press, 2000. 916p.

KAWAKAMI, S.I.; YAMADA, T.; NAKANISHI, N.; CAI, Y. Feeding latic acid bacteria and yeast on growth and diarrhea of Holstein calves. Journal of Animal Veterinary Advances, v. 9, p. 1112-1114, 2010.

KIM, M.K.; LEE, H.G.; PARK, J.A.; KANG, S.K.; CHOI, Y.J. Effect of feeding direct-fed microbial as an alternative to antibiotics for the prophylaxis of calf diarrhea in Holstein calves. Asian-Australasian Journal Animal Science, v.24, n.5, p.643-649, 2011.

KOWALSKI, Z.M.; GORKA, P.; SCLAGHECK, A.; JAGUSIAK, W.; MICEK, P.; STRZETELSKI, J. Performance of Holstein calves fed milk-replacer and starter mixture supplemented with probiotic feed additive. Journal of Animal and Feed Sciences, v.18, p.399-411, 2009.
LARSON, L.L.; OWEN, F.G.; ALBRIGHT, L.L.; APLEMAN, R.D.; LAMB, R.C.; MULLER, L.D. Guidelines toward more uniformity in measuring and reporting calf experimental data. Journal of Dairy Science, v.60, p.989-991, 1977.

MEYER, P.M.; PIRES, A.V.; BAGALDO, A.R.; SIMAS, J.M.C.; SUSIN, I. Adição de probiótico ao leite integral ou sucedâneo e desempenho de bezerros da raça holandesa. Scientia Agricola, v.58, n.2, p.215-221, 2001.

MOHRI, M.; SHARIFI, K.; EIDI, S. Hematology and serum biochemistry of Holstein dairy calves: age related changes and comparison with blood composition in adults. Research in Veterinary

Science, v.83, p.30-39, 2006.

NATIONAL ANIMAL HEALTH MONITORING SYSTEM - NAHSS.

Reference of dairy cattle health and management practices in the United States. Fort Collins, 2007. 1007p.

QUIGLEY, J.D. III. Raising replacement heifers from birth to weaning. Advances in Dairy Technology, v.9, p.285-314, 1997.

QUIGLEY, J.D. III.; STROHBEHN, R.E.; KOST, C.J.; O’BRIEN, M.M. Formulation of colostrum supplements, colostrum replacers and acquisition of passive immunity in neonatal calves. Journal of Dairy Science, v.84, p.2059$2065,2001$.

RIDELL, J.B.; GALLEGOS, A.J.; HARMON, D.L.; MCLEOD, K.R. Addition of a Bacillus based probiotic to the diet of pre ruminant calves: Influence on growth, health, and blood parameters.

The Journal Applied Research Veterinary Medicine, v.8, n.1, p.212$221,2010$. 
Rev. Bras. Saúde Prod. Anim., Salvador, v.17, n.3, p.508-519 jul./set., $2016 \quad \underline{\text { http://www.rbspa.ufba.br }}$ ISSN 15199940

ROSMINI, M.R., SEQUEIRA, G.J., GUERRERO-LEGARRETA, I., MARTÍ, L.E., DALLA-SANTINA, R., FRIZZO, L., BONAZZA, J.C., 2004. Probiotic production for meat animals: importance of using indigenous intestinal microbiota. Revista Mexicana de Ingenieria Química, v.3, p.181-191, 2004.

SCHAREK, L.; GUTH, J.; REITER, K.; WEYRAUCH, K.D.; TARAS, D.; SCHWERK, P.; SCHIERACK, P.; SCHMIDT, M.F.G.; WIELER, L.H.; TEDIN, K. Influence of a probiotic Enterococcus faecium strain on development of the immune system of sows and piglets. Veterinary immunology and immunopathology, v.105, p.151-161, 2005.

STAMEY, J.A.; JANOVICK, N.A.; KERTZ, A.F.; DRACKLEY, J.K. Influence of starter protein content on growth of dairy calves in an enhanced early nutrition program. Journal of Dairy Science, v.95, p.3327-3336, 2012.

SUN, P.; WANG, J.Q.; ZHANG, H.T. Effects of Bacillus subtilis natto on performance and immune function of preweaning calves. Journal of Dairy Science, v.93, p.5851-5855, 2010.

TAO, S., A.P.A. MONTEIRO, I.M. THOMPSON, M.J. HAYEN, G.E. DAHL. Effect of late-gestation maternal heat stress on growth and immune function of dairy calves. Journal of Dairy Science, v.95, p.7128-7136, 2012.

TIMMERMAN, H.M.; MULDER, L.; EVERTS, H.; VAN ESPEN, D.C.; VAN DER WAL, E.; KLAASSEN, G. Health and growth of veal calves fed milk replacers with or without probiotics. Journal of Dairy Science, v.88, p.2154 2165, 2005.
VANBELLE, M.; TELLER, E.; FOCANT, M. Probiotics in animal nutrition: a review. Archives of Animal Nutrition, n.7, p.543-567, 1990.

Data de recebimento: $23 / 03 / 2016$

Data de aprovação: 28/07/2016 